\title{
A multicenter approach to evaluate omalizumab effectiveness in Samter's triad
}

\author{
Paolo Cameli', Miriana d'Alessandro' ${ }^{1}$, Laura Bergantini' ${ }^{1}$, Elena Silvestri², Arianna Romaldi ${ }^{3}$, \\ Giacomo Emmi², Paola Parronchi ${ }^{3}$, Elena Bargagli ${ }^{1}$ \\ ${ }^{1}$ Respiratory Diseases Unit, Department of Medical and Surgical Sciences and Neurosciences, University of Siena; \\ ${ }^{2}$ Interdisciplinary Internal Medicine, Department of Experimental and Clinical Medicine, University of Florence; \\ ${ }^{3}$ Immunology and Cell Therapies Unit Department of Experimental and Clinical Medicine, University of Florence, \\ Italy
}

\begin{abstract}
Omalizumab proved to be very effective in improving control of severe atopic asthma. Many small-sized studies suggested a potential role for omalizumab in the management of aspirin-exacerbated respiratory disease. The aim of this study is to describe the effectiveness of omalizumab in a multicentre group of patients with Samter's triad. We retrospectively enrolled eight patients ( 5 females) with Samter's triad who underwent at least one year of omalizumab therapy. Clinical data, functional parameters and questionnaires for asthma and nasal polyposis control were collected at baseline and
\end{abstract}

Correspondence: Paolo Cameli, Respiratory Diseases Unit, Department of Medicine, Surgery and Neurosciences, University of Siena, Viale Bracci 1, Siena 53100, Italy.

E-mail: paolocameli88@gmail.com

Key words: Omalizumab; Samter's triad; aspirin intolerance; anti-IgE; nasal polyposis.

Contributions: All the authors made a substantive intellectual contribution, performed part of the experiments. All the authors have read and approved the final version of the manuscript and agreed to be accountable for all aspects of the work.

Conflict of interest: The authors declare no conflict of interest.

Availability of data and materials: All data generated or analyzed during this study are included in this published article.

Funding: None.

Informed consent: Written informed consent was acquired from every patient included in the study for anonymized patient information to be published in this article.

Received for publication: 21 May 2020.

Accepted for publication: 23 June 2020.

${ }^{\circ}$ Copyright: the Author(s), 2020

Licensee PAGEPress, Italy

Monaldi Archives for Chest Disease 2020; 90:1397

doi: 10.4081/monaldi.2020.1397

This article is distributed under the terms of the Creative Commons Attribution Noncommercial License (by-nc 4.0) which permits any noncommercial use, distribution, and reproduction in any medium provided the original author(s) and source are credited. follow-up. We observed a significant reduction of moderate-to-severe asthma exacerbations, together with an increase of FEV1 and a reduction of steroids intake. An improvement in asthma control and nasal symptoms was also reported. This multicenter study confirms the effectiveness of omalizumab in patients affected by Samter's triad. Omalizumab may represent a potential therapeutic option for the management of this disease.

\section{Introduction}

Aspirin-exacerbated respiratory diseases (AERDs) is a group of respiratory disorders characterized by a non- $\operatorname{IgE}$ mediated immunological intolerance to acetylsalicilic acid. Among AERDs, the most recognizable disease entity is the so-called Samter's triad: bronchial asthma, chronic rhinosinusitis with nasal polyposis (CRSwNP) and intolerance to aspirin or other NSAIDs. Firstly described by Widal [1], the majority of patients affected by Samter's triad shows specific clinical features, with a typical onset in the thirdfourth decade of life [2]. Asthma is often refractory to inhaled therapy, including high dose inhaled corticosteroids (ICS) plus longacting beta2-agonist and/or antimuscarinic agents, while CRSwNP can be massive, requiring multiple surgical treatments $[3,4]$.

Due to these clinical features, Samter's triad is estimated to contribute to the $15 \%$ of severe asthmatic population, and, therefore, may be considered a specific indication for biologic treatment [5]. However, limited data is available on this topic [6]. Among biologic drugs approved for the treatment of asthma, anti-IgE omalizumab was reported to significantly improve asthma control and quality of life in these patients, even though only in limited and monocentric case-series [7-9]. Moreover, a significant reduction in urinary concentrations of LTE4 and PGD2 in patients treated with omalizumab was reported, suggesting a specific activity of this drug in regulating this specific type of inflammation [10].

The aim of this multicentre study was to investigate the effectiveness of omalizumab in terms of clinical and functional improvement in patients affected by Samter's triad.

\section{Methods}

\section{Study design and population}

In this multicentre study, we retrospectively recruited patients diagnosed with Samter's triad and treated with omalizumab. 
Patients were enrolled from three Centres: Respiratory Diseases Unit of Siena University, Immunology and Cell Therapies Unit and Interdisciplinary Internal Medicine of the Careggi University Hospital, Florence, Italy. Demographic, clinical, functional, immunological and therapeutic data was collected and entered in an ad hoc created electronic database shared by all the centres. Clinical data comprised asthma exacerbation rate and severity. Specific questionnaires for evaluation of asthma and CRSwNP control (Asthma Control Test, ACT, and 22-item SinoNasal Outcome Test, SNOT22) were reviewed from clinical records.

Pulmonary functional tests (PFTs) were collected at baseline and after 1 year of therapy. Informed consent was acquired from every patient included in the study.

\section{PFTs}

The following lung function parameters were recorded according to ATS/ERS standards [11,12], with corrections for temperature and barometric pressure: FEV1, FVC, FEV1/FVC, PEF, FEF $25-75 \%$.

\section{Statistical analysis}

Data was expressed as mean \pm standard deviation (SD). Non parametric tests (Mann-Whitney and Wilcoxon ranked test) were used to perform data analysis. Microsoft Excel and Graphpad Prism
5.0 for Windows were used for statistical analysis and to plot the figures.

\section{Results}

We retrospectively enrolled 8 patients ( 5 females, $54.8 \pm 11.6$ years old) in this study. Demographic features, clinical and immunological parameters and functional data are reported in Table 1.

The majority of our patients were non-smoker females: the clinical onset of disease fell in the fourth decade of life, as expected. Despite general moderate-to-high dosage of ICS and oral corticosteroids (OCS) assumption as maintenance therapy in $3 / 8$ patients, we observed a suboptimal control of asthma before therapy, as reported by moderate-severe exacerbation annual rate. Baseline ACT was available in all cases, while SNOT22 score was collected in $6 / 8$ patients.

Baseline post bronchodilator PFTs showed a mild obstructive impairment of lung volumes, on average.

In our population, 5 patients did not show sensibilization to perennial allergens and were treated with omalizumab at the dosage of $300 \mathrm{mg} /$ die because affected by chronic spontaneous urticaria (CSU). No significant differences in terms of age, sex, eosinophil

Table 1. Demographic and clinical features, immunological and functional parameters of the study population at baseline, stratified according to atopic status.

\begin{tabular}{|c|c|c|c|c|}
\hline Parameters & Total population & Non-atopic & Atopic & p-value \\
\hline Number & 8 & 5 & 3 & \\
\hline Female sex (F) & 5 & 3 & 2 & 1.00 \\
\hline Age (years) & $56.7 \pm 11.9$ & $54.2 \pm 10.4$ & $61 \pm 13.4$ & 0.5714 \\
\hline $\begin{array}{l}\text { Smoking status (pack/year) } \\
\text { - Current } \\
\text { - Former } \\
\text { - Never }\end{array}$ & $\begin{array}{c}1.3 \pm 2.3 \\
1 \\
2 \\
5\end{array}$ & $\begin{array}{c}1.8 \pm 2.7 \\
1 \\
1 \\
3\end{array}$ & $\begin{array}{c}0.6 \pm 0.9 \\
0 \\
1 \\
2\end{array}$ & 0.8633 \\
\hline BMI $\left(\mathrm{kg} / \mathrm{m}^{2}\right)$ & $23.5 \pm 1.6$ & $24 \pm 1.5$ & $22.8 \pm 1.5$ & 0.5714 \\
\hline Age at onset (years) & $37.6 \pm 16.3$ & $36.4 \pm 8.8$ & $39.6 \pm 24$ & 0.6528 \\
\hline \multicolumn{5}{|l|}{ Immunological data } \\
\hline Total serum IgE (IU/ml) & $167.9 \pm 122.9$ & $142.3 \pm 65.1$ & $202 \pm 166$ & 0.8571 \\
\hline $\begin{array}{l}\text { Eosinophil cell count cell/mm } \mathrm{mm}^{3} \\
(\%)\end{array}$ & $\begin{array}{c}507.1 \pm 307.3 \\
6.1 \pm 3.6\end{array}$ & $\begin{aligned} 602.5 & \pm 342.7 \\
6.5 & \pm 4.4\end{aligned}$ & $\begin{array}{c}380 \pm 180 \\
5.5 \pm 2.8\end{array}$ & $\begin{array}{l}0.6286 \\
0.8571\end{array}$ \\
\hline \multicolumn{5}{|l|}{ Clinical features } \\
\hline No of moderate-severe exacerbations & $2.8 \pm 1.1$ & $2.4 \pm 0.5$ & $4 \pm 0.8$ & 0.0668 \\
\hline ACT score & $17.8 \pm 4.6$ & $19.4 \pm 5$ & $15.3 \pm 2$ & 0.4534 \\
\hline SNOT22 score & $29 \pm 8.8$ & $29.5 \pm 10.4$ & $28 \pm 4$ & 1.00 \\
\hline \multicolumn{5}{|l|}{ PFTs $^{\circ}$} \\
\hline $\begin{array}{l}\text { FEV1 l } \\
(\%)\end{array}$ & $\begin{array}{c}2.3 \pm 0.9 \\
(77.2 \pm 14.4)\end{array}$ & $\begin{array}{c}2.4 \pm 0.9 \\
(82.5 \pm 14.4)\end{array}$ & $\begin{array}{c}2 \pm 0.8 \\
(68.3 \pm 9.4)\end{array}$ & $\begin{array}{l}0.5714 \\
0.3929\end{array}$ \\
\hline $\begin{array}{l}\text { FVC I } \\
(\%)\end{array}$ & $\begin{array}{c}3.6 \pm 1.2 \\
(95.3 \pm 8.5)\end{array}$ & $\begin{array}{c}3.4 \pm 1.2 \\
(94.3 \pm 10.9)\end{array}$ & $\begin{array}{c}3.3 \pm 1.1 \\
(96.8 \pm 0.4)\end{array}$ & $\begin{array}{l}0.7857 \\
0.7000\end{array}$ \\
\hline FEV1/FVC & $64.6 \pm 8.2$ & $67.9 \pm 7$ & $59.1 \pm 6.2$ & 0.2500 \\
\hline $\begin{array}{l}\mathrm{PEF} 1 / \mathrm{min} \\
(\%)\end{array}$ & $\begin{array}{c}6.5 \pm 2.2 \\
82.2 \pm 12.5\end{array}$ & $\begin{array}{l}6.9 \pm 2.4 \\
87 \pm 14.3\end{array}$ & $\begin{array}{l}5.8 \pm 1.4 \\
75 \pm 1.4\end{array}$ & $\begin{array}{l}0.5714 \\
0.4563\end{array}$ \\
\hline $\begin{array}{l}\text { FEF } 25-75 \% \mathrm{l} / \mathrm{s} \\
(\%)\end{array}$ & $\begin{array}{c}1.6 \pm 1 \\
45.4 \pm 22.9\end{array}$ & $\begin{array}{c}1.9 \pm 1.1 \\
54.9 \pm 25.1\end{array}$ & $\begin{array}{l}1.1 \pm 0.5 \\
32.8 \pm 10\end{array}$ & $\begin{array}{l}0.4000 \\
0.4250\end{array}$ \\
\hline
\end{tabular}

*p-value calculated between atopic and non-atopic subgroups; ${ }^{\circ}$ all functional data was measured post-bronchodilator. 
cell count and serum total IgE were found between CSU and notCSU patients.

At follow-up $(454.8 \pm 208.7$ days, mean \pm SD), we observed a significant improvement of asthma control, as showed by the reduction of moderate-to-severe exacerbation rate $(\mathrm{p}=0.0103)$, with $4 / 8$ patients not reporting any respiratory events during the treatment (Figure 1). Regarding inhalation therapy, we reported a non significant reduction of ICS dosage and Short-Acting Beta Agonists (SABA) as rescue therapy ( $\mathrm{p}=0.2500$ and $\mathrm{p}=0.0975$, respectively). Among the three patients with OCS as maintenance therapy, 1 patient discontinued steroid assumption and 1 patient halved daily dosage. The third one discontinued OCS, but experienced two moderate exacerbations requiring temporary reintroduction of OCS. None of the patients took aspirin or other NSAIDs during the observation time.

Concerning PFTs, we observed a significant increase of postbd FEV1, both in absolute and percentage of predicted values $(p=0.0156$ and $p=0.0078$, respectively) (Figure 2$)$, while other functional parameters (FVC, PEF, FEF25-75 and FEV1/FVC ratio) improved, without reaching statistical significance (Table 2).

Regarding clinical questionnaires, our results showed an improvement of ACT and SNOT22 scores $(\mathrm{p}=0.0355$ and $\mathrm{p}=0.0313$, respectively) (Figure 3 ). None of the patients underwent sinus surgery during the observation time. None of the patients discontinued omalizumab therapy due to side effects. No significant averse events were reported during the observation time.

\section{Discussion}

In the present study, we described the experience of 8 patients affected by Samter's triad treated with omalizumab. Study population was recruited in three Centres specialized in diagnosis and management of severe asthmatic patients. Our results suggest a reliable effectiveness of omalizumab in improving asthma control, reducing exacerbation rate and need for OCS and relieving also CRSwNP symptoms.

The potential efficacy of omalizumab in this specific setting of patients has been already reported in literature $[7,9,10,13]$; however, all published studies were monocentric and predominantly consisted of case reports or little-sized case series. To our knowledge, this is the first multicenter study assessing this topic and, therefore, despite our limited sample size, provides further strength on the potential utility of omalizumab in Samter's triad. Moreover, 5 out of 8 patients included in the study didn't show any sensitization to perennial allergens and were treated with omalizumab due to CSU,

Table 2. Comparison of pulmonary functional parameters between baseline and 1-year of omalizumab treatment.

\begin{tabular}{lccc}
\hline PFT parameters & Baseline & 1-year omalivumab & p-value* \\
FEV1 l & $2.3 \pm 0.9$ & $2.6 \pm 0.9$ & 0.0156 \\
$(\%)$ & $(77.2 \pm 14.4)$ & $(89.7 \pm 9.2)$ & 0.0078 \\
FVC 1 & $3.6 \pm 1.2$ & $3.8 \pm 1$ & 0.1563 \\
$(\%)$ & $(95.3 \pm 8.5)$ & $(109.3 \pm 9.1)$ & 0.1250 \\
\hline FEV1/FVC & $64.6 \pm 8.2$ & $68 \pm 7.5$ & 0.0585 \\
PEF l/min & $6.5 \pm 2.4$ & $7.3 \pm 2.4$ & 0.1250 \\
$(\%)$ & $82.2 \pm 12.5$ & $93.8 \pm 7.5$ & 0.1250 \\
\hline FEF $25-75 \%$ l/s & $1.6 \pm 1.1$ & $1.7 \pm 1.0$ & 0.2188 \\
$(\%)$ & $45.4 \pm 22.9$ & $48.9 \pm 19.6$ & 0.5625 \\
\hline
\end{tabular}

showing the same results in terms of clinical efficacy on asthma control. On this field, our study confirmed and enlarged the result of a previous case report, describing the effectiveness of omalizumab in a non-atopic 15 -year old female patient affected with Samters-triad and CSU [14]. Therefore, despite the limited evidence due to small samples size and pediatric setting, our study suggests that omalizumab could be useful in the management of patients

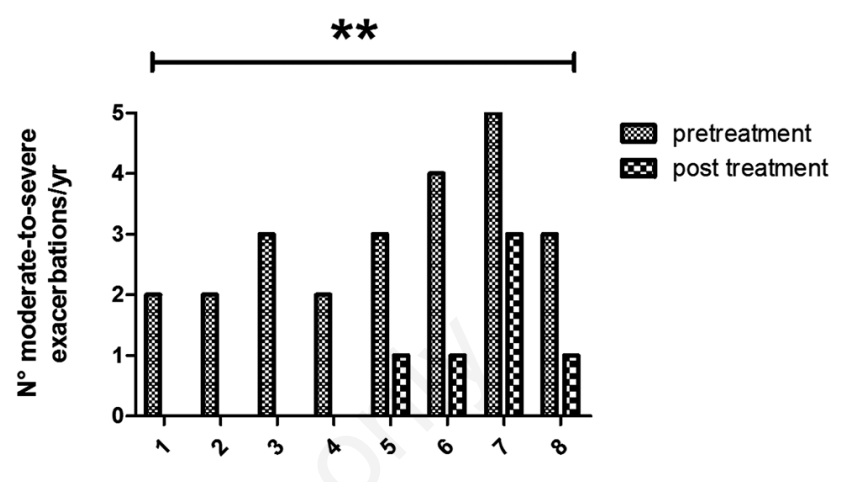

**, $\mathrm{P}=0.0103$

Figure 1. Comparison of moderate-to-severe exacerbation events before and after one year of treatment with omalizumab.
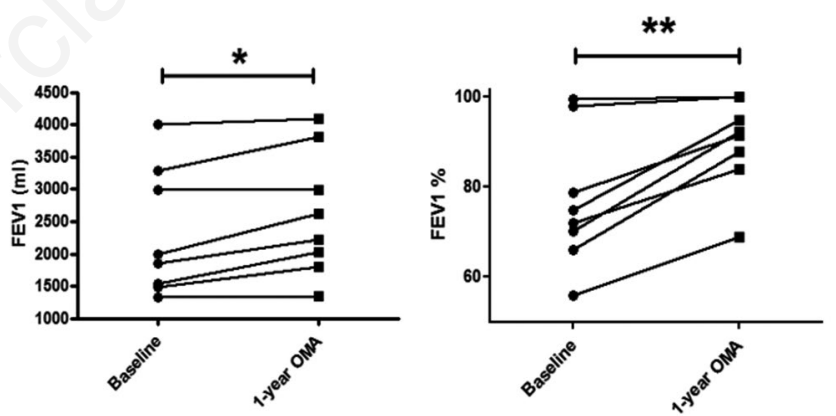

*, $\mathrm{P}=0.0156 ;{ }^{* *}, \mathrm{P}=0.0078$.

Figure 2. Evaluation of post-bronchodilator FEV1 (on the left: absolute values; on the right: percentage of predicted values) at baseline and at 1-year of follow-up.
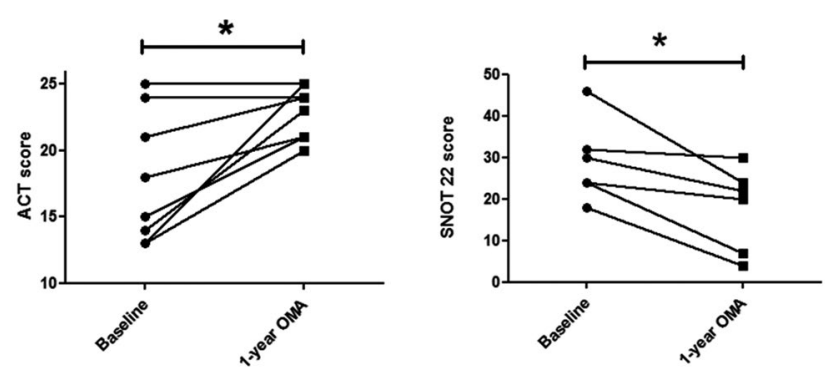

*, $\mathrm{P}<0.05$.

Figure 3. Comparison of ACT and SNOT22 scores before and after one year of treatment with omalizumab. 
affected by Samter's triad, regardless their atopic status. The specific effects of omalizumab in the pathogenesis of Samter's triad have not been clarified, probably due to the limited available data. However, pleiotropic effects of omalizumab in multiple $\operatorname{IgE}$ and non-IgE mediated diseases have been repeatedly demonstrated (such as non-atopic and non eosinophilic asthma), supporting further areas of application for this biological treatment. About Samter's triad, a single study demonstrated a significant reduction of specific disease biomarkers (such as urinary cysteinyl leukotriene) after treatment exposure, suggesting the potential of omalizumab in interfering with arachidonic acid metabolism [10].

Unfortunately, few data is available on the efficacy of other biological therapies on Samter's triad; conflicting results have been published on mepolizumab efficacy, while dupilumab showed promising results on sinus symptoms $[6,15,16]$.

Interestingly, we also observed a significant improvement of CRSwNP symptoms and none of our patients underwent to sinus surgery during the observation time. Although it was limited by sample size, SNOT22 values between atopic and non atopic patients did not show any differences at statistical analysis. These data are surely interesting and are in line with previous reports, that demonstrated the efficacy of omalizumab in reducing symptomatic burden of CRSwNP, regardless the atopic status of patients $[14,15]$. On this topic, two phase III RCTs (POLYP 1 and 2), evaluating the efficacy of omalizumab on CRSwNP regardless diagnosis of asthma or atopic status, have been recently completed and results will shortly be published (NCT03280550 and NCT03280537).

This study has some limitations. First, the sample size, despite its multicenter design. Second, the retrospective nature of the study is typically exposed to referral and reporting bias, although the participating Centres are all highly experienced in the management of severe asthma, ensuring an accurate selection of patients.

In conclusion, this multicenter study confirms the efficacy of omalizumab in a specific disease entity as Samter's triad, regardless the atopic status of the patients. However, a larger, multicenter and prospective study is needed to strengthen these findings and confirm the therapeutic indication for omalizumab in this specific subgroup of asthmatic patients. The potential utility of omalizumab in the management of CRSwNP has been assessed and will be further evaluated in oncoming RCTs.

\section{References.}

1. Widal F, Abrami P, Lermoyez J. First complete description of the aspirin idiosyncrasy-asthma-nasal polyposis syndrome (plus urticaria) - 1922 (with a note on aspirin desensitization). J Asthma 1987;24:297-300.

2. Berges-Gimeno MP, Simon RA, Stevenson DD. The natural history and clinical characteristics of aspirin-exacerbated respiratory disease. Ann Allergy Asthma Immunol 2002;89: 474-8.

3. Kim S-D, Cho K-S. Samter's Triad: State of the Art. Clin Exp Otorhinolaryngol 2018;11:71-80.

4. Samter M, Beers RF. Intolerance to aspirin. Clinical studies and consideration of its pathogenesis. Ann Intern Med 1968;68:975-83.

5. Rajan JP, Wineinger NE, Stevenson DD, White AA. Prevalence of aspirin-exacerbated respiratory disease among asthmatic patients: A meta-analysis of the literature. J Allergy Clin Immunol 2015;135:676-681.e1.

6. Tuttle KL, Buchheit KM, Laidlaw TM, Cahill KN. A retrospective analysis of mepolizumab in subjects with aspirinexacerbated respiratory disease. J Allergy Clin Immunol Pract 2018;6:1045-7.

7. Cameli P, Perruzza M, Salvini M, et al. Omalizumab treatment in Samter's triad: case series and review of the literature. Eur Rev Med Pharmacol Sci 2019;23:8124-9.

8. Yalcin AD, Uçar S, Gumuslu S, Strauss LG. Effects of omalizumab on eosinophil cationic peptide, 25-hydroxyvitaminD, IL- $1 \beta$ and sCD200 in cases of Samter's syndrome: 36 months follow-up. Immunopharmacol Immunotoxicol 2013;35:524-7.

9. Ardusso LRF, Neffen H. A 12 $\frac{1}{2} 2$-year journey of a patient with Samter triad syndrome and sporadic omalizumab use. Ann Allergy Asthma Immunol 2015;115:454-6.

10. Hayashi H, Mitsui C, Nakatani E, Fukutomi Y, Kajiwara K, Watai $\mathrm{K}$, et al. Omalizumab reduces cysteinyl leukotriene and $9 \alpha, 11 \beta$-prostaglandin F2 overproduction in aspirinexacerbated respiratory disease. J Allergy Clin Immunol 2016;137:1585-1587.e4.

11. Miller MR, Crapo R, Hankinson J, Brusasco V, Burgos F, Casaburi $\mathrm{R}$, et al. General considerations for lung function testing. Eur Respir J 2005;26:153-61.

12. Graham BL, Brusasco V, Burgos F, Cooper BG, Jensen R, Kendrick A, et al. 2017 ERS/ATS standards for single-breath carbon monoxide uptake in the lung. Eur Respir J 2017;49.

13. Bergmann K-C, Zuberbier T, Church MK. Omalizumab in the treatment of aspirin-exacerbated respiratory disease. J Allergy Clin Immunol Pract 2015;3:459-60.

14. Porcaro F, Di Marco A, Cutrera R. Omalizumab in patient with aspirin exacerbated respiratory disease and chronic idiopathic urticaria. Pediatr Pulmonol 2017;52:E26-8.

15. Eid RC, Wudneh E, Zahid S, et al. Poor control of asthma symptoms with interleukin-5 inhibitors in four patients with aspirin-exacerbated respiratory disease. Ann Allergy Asthma Immunol 2020;124:102-4.

16. Taniguchi M, Mitsui C, Hayashi H, et al. Aspirin-exacerbated respiratory disease (AERD): Current understanding of AERD. Allergol Int 2019;68:289-95. 